\title{
Simulating the Macroeconomic Impact of Future Water Scarcity: an Assessment of Alternative Scenarios
}

\author{
Roberto Roson \\ Ca' Foscari University, Venice and IEFE, Bocconi University, Milan \\ Richard Damania \\ The World Bank, Washington D.C.
}

February 16, 2016

\begin{abstract}
In this paper we consider some of the economic implications of climate change scenarios as described in the Shared Socioeconomic Pathways (SSPs). By comparing potential water demand with estimates of (sustainable) water availability in different regions, we identify regions that are likely to be constrained in their future economic growth potential by the scarcity of water resources. We assess the macroeconomic impact of water scarcity under alternative allocation rules finding that, by assigning more water to sectors in which it has a higher value, shifting production to less water intensive sectors, and importing more water intensive goods, constrained regions can effectively neutralize these water related climate risks and adapt to a changing water environment. However, this adaptation effort is likely to imply some radical changes in water management policies.
\end{abstract}

\section{Keywords:}

Water, Economic Growth, Shared Socio-economic Pathways, Computable General Equilibrium, Virtual Water Trade.

JEL Codes: C68, F18, F43, O11, Q01, Q25, Q32, Q56. 


\section{Introduction}

Currently almost a quarter of humanity, 1.6 billion people, live in countries of physical water scarcity, and this number may double in two decades. Population growth, urbanization, and economic expansion will heighten scarcities where water already is in short supply. Climate change, superimposed on this backdrop of water scarcity and excessive variability in many parts of the world, will perhaps magnify the challenge of managing a complex natural resource. In fact water is the primary channel through which many of the impacts of climate change will be felt - through variations in rainfall, snowmelt, storm surges, and rising seas.

This paper seeks to explore this issue in more detail by investigating some of the macroeconomic implications of possible climate and growth induced future water scarcity. In order to do so, the paper combines projections of climate impacts on water supplies, from a suite of global climate models, with a conventional computable general equilibrium that incorporates water as a factor of production and a consumption good. The analysis is based on a comparison between potential demand for water and estimated water availability in a number of climate change scenarios. The feasibility of growth scenarios are examined when there is a water supply shock.

Water availability is calculated using the Global Change Assessment Models (GCAM). Three different climatic Global Circulation Models (GCMs) are used as inputs - CCSM, FIO, and GISS - to feed a complex hydrologic model. These encompass the range of model runoff uncertainties and cover the extremes of wet, moderate and dry projections from the GCAM model ensemble. The main output of these models is an estimate of runoff and water inflows for 15 sub-regions of the world. The models suggest that the global supply of water (in aggregate) is not significantly impacted by climate change, reflecting the fact that the water cycle is a closed dynamic system. However there are vast regional variations in run-off. More countries than not will experience declines in river flow, putting major stress on irrigated agriculture (see Figure 1 for an example of an output). Groundwater recharge, being heavily dependent on river flows, precipitation levels, and, in some regions, snowfall, is also likely to decline in these countries. Even regions which are likely to experience increases in precipitation may not see benefits. More rainfall will be partially offset by greater evaporation due to warmer temperatures. The supply side impacts are most severe in the Middle East, parts of Africa and Asia, with most of Europe and North America largely unaffected.

The analysis focuses on the consequences of changing runoff. For the purposes of this study, sustainable (renewable) water supply is defined as the total yearly runoff (where necessary integrated by water inflow) within a given region, and scenarios are considered in which this is the only available source of water. Therefore, the possible exploitation of non-renewable water resources (e.g., "fossil water") is ruled out, whereas the adoption of unconventional water supply (e.g., desalination, recycling, harvesting) is indirectly accounted for as improvements in water efficiency (fresh water needed per unit of economic activity). 


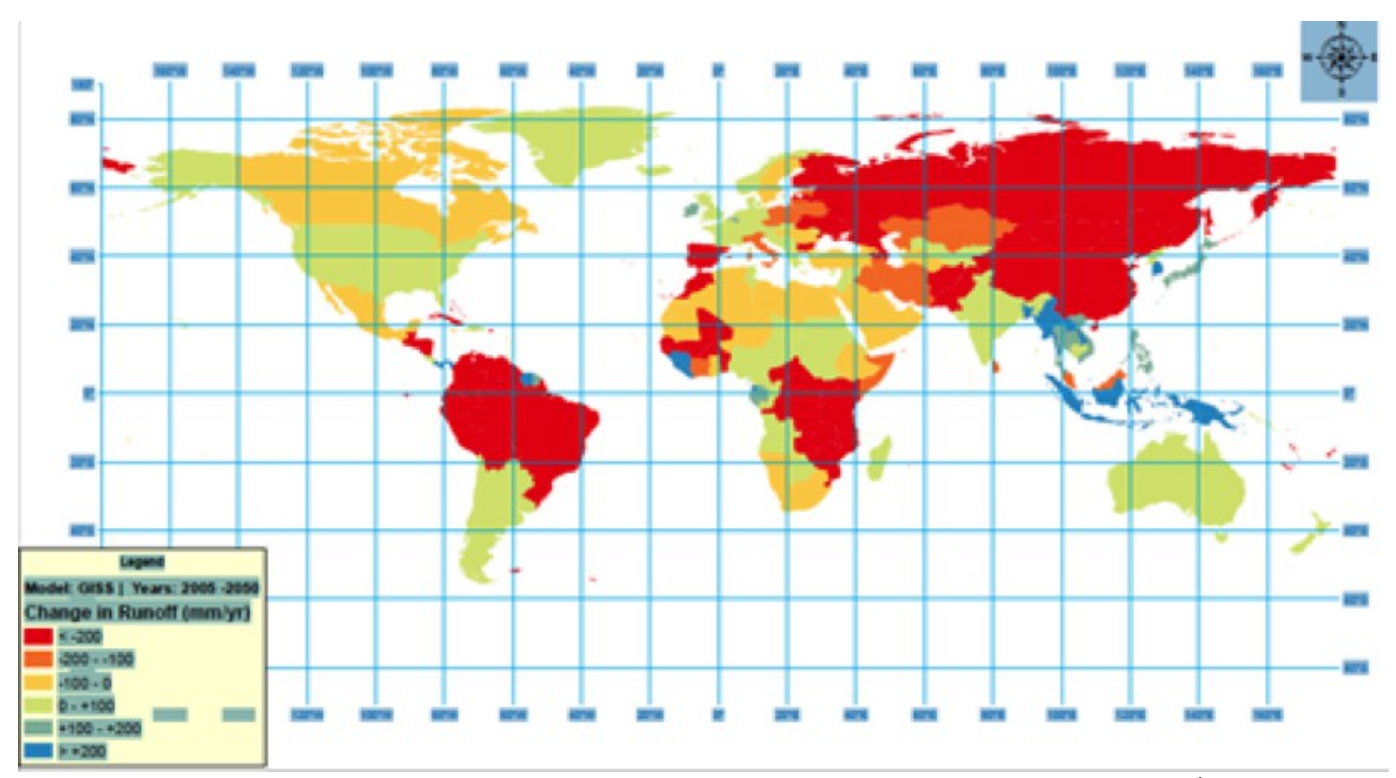

Figure 1 - Change in global runoff by country (2005-2050)

A global computable general equilibrium (CGE) model is used to assess water demand, recognizing its endogenous nature. The demand for water partly depends upon economic structure and income, which are in turn endogenous to available water supplies. The conclusions of the analysis are striking and highlight further the importance of water management policies. With water in short supply, the impact depends mainly on the policy regime.

The scenarios of economic development (the SSPs) that have been proposed to define different climate change futures have ignored water availability. The analysis presented in this paper suggests that underlying assumptions of sustained economic growth, especially for developing countries, are incompatible with the implied and available supplies of water. This underlines the need to consider resource availability and constraints when articulating scenarios.

The analysis begins by considering a business as usual scenario where water is managed under current regimes. In this scenario, the expected global damages are small relative to the expected global GDP in 2050: about 0.2 to 0.5 percent of global GDP in that year. But that estimate is misleading, because significant variations exist between regions. Northern Europe and North America where much of global GDP is produced, experience negligible damages in some scenarios and none in most. The bulk of losses are in the Middle East, North Africa, Central Asia, and South Asia and the magnitude of the loss is largely driven by the level of the water deficit. In the most arid regions the projected percentage losses are large and imply that baseline growth projections cannot be met.

In the next scenarios, when governments respond to water shortages by allocating a portion of water to more highly valued uses, losses decline dramatically and may even vanish. Indeed, in some cases, baseline growth projections are even exceeded. The implication is that the benefits to managing water resources as a valuable economic resource are considerable. Even if only a part of water use is allocated based on its economic price that brings supply and demand into balance, many of the problems of climate and socioeconomic-related scarcity will be resolved. In sum, the overarching policy implication is that prudent management of water resources (at broad spatial scales) could help neutralize many of the water-scarcity induced costs of climate change.

1 Note that these are changes in runoff. The eventual effect depends on baseline precipitation. For instance a $100 \mathrm{~mm}$ decline in runoff has limited impact if baseline rainfall is $3000 \mathrm{~mm}$ as in Colombia rather than $300 \mathrm{~mm}$ as in Chad. 
The remainder of this paper is organized as follows. Section 2 provides a brief review of the literature. Section 3 simulates industry-wide water intensity (use) coefficients and briefly explores how these have varied through time, sections 4 and 5 explore impacts of water supply-side shocks on economic growth and feedback effects on water demand and how these respond to policy changes. Section 6 deals with changes in industry composition and the virtual water trade, while Section 7 concludes.

\section{Related literature}

This paper is related to a significant body of research on the economic impacts of climate change. Broadly three approaches appear to dominate the literature: large integrated assessment models that combine physical and economic models, cross-country regression analyses and computable general equilibrium models.

The traditional approach to assessing the economic costs of climate change is through the large integrated assessment models (IAMs), that use reduced form equations to capture long term perspectives, to the end of this century and beyond (e.g. Nordhaus, 1994, 2007, 2010; Tol, 2005; Stern, 2007; Agrawala et al., 2011). Most of these studies have a stylized representation of the economy focusing on projections of climate change impacts over time. They often include highly aggregated integrated structures, with a climate change induced damage function represented by a single or series of equations. The aggregated results are useful for informing higher level policy debates on the balance between mitigation and adaptation, but provide less information needed to guide policy at the sector and country levels.

An alternative approach seeks evidence through cross-country panel regressions between country short term (annual) economic growth rates or levels and climate related variables. Dell et al. (2012) were perhaps the first to investigate the effects of climate variability (temperature and precipitation), on GDP per capita growth. The study finds that for poor countries, as a group, the effect of a one degree increase in temperature is to reduce growth by 1.4 percent. The effects on richer (and mainly temperate) countries is smaller and less well determined in the regressions. It should be noted that Dell et al. do not find a link between precipitation and GDP growth. In contrast, in a closely related study Brown et al., (2013) allow for temporal and spatial variation in precipitation and find that a $1 \%$ increase in drought exposure results in a decline in GDP per capita of $2.7 \%$. Overall these studies are valuable in pointing to a pathway by which climate change could have impacts. But there are some caveats that need to be noted. First the econometric estimates can be criticized on a number of grounds, such as: using linear functions where non-linearity is more likely to be the case; not taking account of inter-annual variability of temperature and rainfall and their interdependency, and not allowing for individual country effects. Furthermore none of these paper indicate causality of impacts, which is a concern over long periods of time in a panel. For instance this leaves open the possibility that the common observations of climate variability and GDP changes are the result of some other unconnected factors such as a structural shifts, that have nothing to do with climate, during a period of rising temperatures.

A smaller strand of literature uses computable general equilibrium (CGE) models to examine the economic implications of climate change impacts with explicit causal links built into the models (e.g. Bosello et al., 2006, 2012, Eboli, Parrado and Roson, 2010, Roson and van der Mensbrugghe, 2012). The use of CGE models to explore water issues has been recently reviewed by Calzadilla et al. (2016). Because CGE models have a more disaggregated structure, they need more information to determine annual equilibria and to run them forward, linking annual changes for more than 40-50 years, becomes 
complex. On the other hand, they are able to track the impacts of climate in a more detailed way than IAMs, which rely on reduced form functions linking impacts to temperature (see, e.g., disaggregated climate impacts estimated by Roson and Sartori, 2016). Recent work at the OECD (OECD, 2015) has attempted to address these issues by combining a CGE model to investigate the economic impacts of climate change with an IAM model (AD-RICE). This approach can also explain how the composition of GDP is affected over time by climate change and how trade patterns may respond. Similarly, Taheripour et al (2015) have developed a version of the GTAP model with detailed modeling of biofuel supply as well as water demand and supply for the South Asia region (Bangladesh, India and Pakistan). Impacts emerge mainly on agricultural GDP in this analysis. The main recommendations of the analysis is one of meeting demand through improvements in water and land productivity as much as possible. Roson and Sartori $(2014,2015)$ use a CGE model in two different works to analyze the consequences of water scarcity induced by climate change in the Mediterranean. They focus, respectively, on impacts in the tourism industry and in agriculture. It is found that more incoming tourists would increase national income but also induce a change in the productive structure. In most countries, the decline in agriculture entails a lower demand for water, counteracting the additional demand for water coming from tourists. Lower agricultural productivity, induced by reduced water availability, also generates negative consequences in terms of real income and welfare, but the magnitude of the loss depends on the share of agricultural activities in the economy and on the stringency of the environmental regulation.

\section{Estimating industrial water intensity}

Most of the demand for water is an indirect demand, as water is mainly needed to produce goods and services, as well as to support the existence of aquatic ecosystems. Therefore, evaluating the future demand for water requires an assessment of the linkage between water use and the level of economic activities. The numerical exercise presented in this paper is based on estimated "water intensity coefficients" (WIC), which express the amount of water consumed (or otherwise "used") per unit of output in different industries in various regions of the world.

Our estimates of water usage by sector draw upon different data sources. Data from the WIOD project (Dietzenbacher et el., 2013), provides industrial output levels and water use in regional industries and households (Genty, Arto, and Neuwahl, 2013). Water usage for agricultural industries has been estimated by combining regionally detailed information available in Mekonnen and Hoekstra (2011) with individual crop-level data elaborated for the European research project WASSERMed (Roson and Sartori, 2015). Water usage for primary production of coal, gas and oil was estimated combining information on water consumption for various technologies (Mielke, Diaz Anadon and Narayanamurti, 2010) with estimates of thermal potential (U.S. Energy Information Administration, 2015). Estimates of municipal water consumption are provided by Mekonnen and Hoekstra (2011).

Industrial water intensity coefficients are summarized in Table $1^{2}$, showing the average usage of water in $\mathrm{m}^{3}$ per unit value of output 2004 (thousands of US\$).

2 Regional data are available on request. 
Table 1 - Average water intensity ( $\left.m^{3} / 1000 U S \$\right)$

\begin{tabular}{|l|r|}
\hline Rice & 31.69 \\
\hline Wheat & 15.03 \\
\hline Cereals & 18.04 \\
\hline Vegetables and Fruits & 7.05 \\
\hline Oil seeds & 12.93 \\
\hline Sugar & 11.31 \\
\hline Other Crops & 3.81 \\
\hline Other Agriculture & 3.98 \\
\hline Extraction & 0.70 \\
\hline Processed Food & 0.04 \\
\hline Textiles & 0.05 \\
\hline Light Manufacturing & 0.03 \\
\hline Heavy Manufacturing & 0.04 \\
\hline Utilities & 0.68 \\
\hline Construction & 0.00 \\
\hline Transport and Comm. & 0.00 \\
\hline Services & 0.00 \\
\hline
\end{tabular}

As expected, the sector where water is most intensively used is agriculture. On the other hand, the inverse of water intensity coefficients gives the values of output per unit of water: the returns on water are significantly higher in non-agricultural industries.

The ratio between water usage and output volume is, of course, time variant. Understanding how water usage changes over time is of fundamental importance in this context, because we want to translate scenarios of economic growth in terms of water demand projections.

To this end, we estimate empirically the relationship between output changes and water intensity coefficients using panel data derived from the WIOD data base. The WIOD provides a series of inputoutput tables for 41 countries/regions for the years 1995-2009, and also provides information on water usage by sector. Combining water usage with industrial output volumes, a time series of WICs can be obtained. As only 12 of the original 35 WIOD industries are reported as water consuming, the result is a bi-dimensional (industry by country) panel with more than 5000 observations (after removing missing data).

We experimented with alternative model formulations, finding that the most satisfying results ${ }^{3}$ are obtained when the annual percentage variation of water intensity coefficients, by industry, is regressed against the annual percentage variation of industrial production levels, industry dummies and regional dummies ${ }^{4}$.

3 R-squared $=0.4267$, adjusted R-squared $=0.4209$. Detailed results available on request.

4 This would mean that the variation trend in water intensity coefficients is region-specific. 
Table 2 - Key regression results

\begin{tabular}{|l|r|r|r|}
\hline Variable & Coefficient & St. Err. & t stat. \\
\hline Output growth \% & -.7396411 & .0124633 & -59.35 \\
\hline Textiles & -1.767063 & .7552951 & -2.34 \\
\hline Chemicals & 1.915836 & .755805 & 2.53 \\
\hline Utilities & 1.913342 & .7686984 & 2.49 \\
\hline Constant & -.0714131 & 1.307679 & -0.05 \\
\hline
\end{tabular}

Table 2 presents some results obtained by regressing the annual percentage variation in the industrial water intensity factor ${ }^{5}$. The constant term is not statistically significant. Instead, some of regional dummies are. The coefficient associated with the industrial output volume is about -0.74 . The implication is that when industrial production rises, then industrial water consumption increases by just $26 \%$ of the output growth ${ }^{6}$. Historically, there have been significant economies of scale and output related efficiency gains in water use. If future use patterns reflect those of the past, it is reasonable to expect roughly equivalent efficiency improvements at least over the medium run.

As for the industry dummies, Table 2 shows that three coefficients are statistically significant. For Textiles the coefficient is -1.77 . This means that industrial water consumption would decrease, unless production levels grow (in a year) more that $6.8 \%{ }^{7}$, which is a strong water efficiency gain indeed. For Chemicals the coefficient is 1.92 . This suggests that industrial water consumption would increase ${ }^{8}$. For Electricity, Gas and Water Supply the coefficient is 1.91: more water would be used to produce electricity and water distribution services.

Restricting the attention to coefficients which have non-zero values in their 95\% confidence interval, it turns out that some countries exhibit quite strong, and positive, trends. Interestingly, these are all countries which have experienced very high GDP growth rates in the period under consideration: China, Estonia, Indonesia, India, Ireland, South Korea, Lithuania, Poland, Russia, Turkey and Taiwan. In the context at hand, the critical issue is whether the observed trend could persist in the long run. As we think that this is unlikely to be the case, we have dropped all regional coefficients in our estimates of future water demand.

\section{Economic growth and potential water demand}

Most of the quantitative modeling exercises of climate change (impacts and policies), undertaken before the $5^{\text {th }}$ Assessment Report of the IPCC (2014) have been based on the SRES scenarios, which are now replaced by the "Representative Concentration Pathways" (RCP) and "Shared Socio-economic Pathways" (SSP). RCPs focus on physical variables and provide time-dependent projections of atmospheric greenhouse gas (GHG) concentrations (van Vuuren et al., 2011). They are representative in

5 For clarity, we omit here the non-statistically significant variables (except the constant term) and all regional dummies.

6 This is because the percentage change in water demand is given by the sum of percentage variation in output (e.g. $+1 \%$ ) and the percentage variation in water intensity (e.g., $-0.74 \%$ ).

7 Let $w=$ water demand, $o=$ output, $i=$ water intensity: $d w / w=d o / o+d i / i=(1-0.74) d o / o-1.77 . d w / w=0=>d o / o=$ $1.77 /(1-0.74)=6.8$.

8 With production $+1 \%$ water consumption $+2.18 \%$, production $+3 \%$ water consumption $+2.7 \%$, production $+5 \%$ water consumption $+3.2 \%$. 
that they are one of several different scenarios that have similar radiative forcing and emissions characteristics.

SSPs focus instead on socio-economic variables and partly overlap with RCPs. SSPs are defined as reference pathways, describing plausible alternative trends in the evolution of society and ecosystems over a century timescale (2000-2100), in the absence of climate change or climate policies (Kriegler et al., 2012; O’Neill et al., 2014). SSPs are differentiated on the basis of pre-specified outcomes (e.g. population, economic development, technologies, preferences, institutional effectiveness). Some of these elements are expressed qualitatively in "narratives", while others will be quantitative. Unfortunately, SSPs have so far not been precisely defined in quantitative terms and their use as baselines for quantitative modeling exercises is therefore problematic. There are very few examples of SSPs being used to guide quantitative assessments of water related impacts. A notable pioneering exercise was undertaken by Hanasaki et al. (2013) who used the Asia-Pacific Integrated Model of the National Institute for Environmental Studies, Japan, to “interpret” the SSP qualitative narratives into quantitative estimates.

In this study, a similar strategy is used, based on a limited set of SSP forecasts of income and population growth, complemented by CGE simulations aimed at enlarging the number of estimated economic variables. The exercise is conducted for two years, 2050 and 2100, and for two SSPs: SSP1 ${ }^{9}$, termed "Sustainability", and SSP ${ }^{10}$, termed "Regional Rivalry". For each combination of year and SSP, growth rates in population and GDP have been assumed, using data from the IIASA SSP repository ${ }^{11}$. By shocking the corresponding parameters in the GTAP CGE model ${ }^{12}$, several other endogenous variables were obtained, like production volumes by industry and region, household consumption, regional investments, exports and imports, income by source, etc.

9 SSP1 is characterized by the following narrative: "Sustainable development proceeds at a reasonably high pace, inequalities are lessened, technological change is rapid and directed toward environmentally friendly processes, including lower carbon energy sources and high productivity of land.”. The possible SRES analogues are B1 and A1T.

"Challenges" for mitigation and adaptation policies are considered to be low.

10 SSP3 is characterized by the following narrative: "Unmitigated emissions are high due to moderate economic growth, a rapidly growing population, and slow technological change in the energy sector, making mitigation difficult. Investments in human capital are low, inequality is high, a regionalized world leads to reduced trade flows, and institutional development is unfavorable, leaving large numbers of people vulnerable to climate change and many parts of the world with low adaptive capacity.” The possible SRES analogue is A2. "Challenges" for mitigation and adaptation policies are considered to be high.

11 https://tntcat.iiasa.ac.at/SspDb/dsd?Action=htmlpage\&page=about .

12 https://www.gtap.agecon.purdue.edu/models/current.asp. The model was calibrated with the GTAP8 database for the year 2004 (aggregated to 14 macro-regions),. 


\section{Table 3 - Projections of Future Water Demand (millions of $m^{3}$ )}

Baseline 2004

N_America C_America S_America W_Europe E_Europe $\quad$ MENA Sahel C_Africa S_Africa C_Asia E_Asia S_Asia SE_Asia Australasia

\begin{tabular}{|c|c|c|c|c|c|c|c|c|c|c|c|c|c|c|}
\hline gricult. & 1320159 & 462666 & \begin{tabular}{|l|}
956679 \\
\end{tabular} & 360114 & 838905 & 533776 & 345160 & 496424 & 276015 & 192685 & 1341460 & 1684088 & 1042806 & 182646 \\
\hline rial & 509594 & 123345 & 172642 & 172151 & 363591 & 508932 & 6400 & 51398 & 57925 & 48604 & 301802 & 111472 & 111377 & 17777 \\
\hline cipal & 38677 & 25540 & 17794 & 16250 & 28695 & 29255 & 2788 & 3263 & 6098 & 5228 & 80122 & 63757 & 24215 & 1605 \\
\hline tal & 1868430 & 611551 & 1147115 & 548516 & 1231191 & 1071963 & 354348 & 551084 & 340038 & 246517 & 1723384 & 1859318 & 1178398 & 202028 \\
\hline
\end{tabular}

2050 SSP1

\begin{tabular}{|c|c|c|c|c|c|c|c|c|c|c|c|c|c|c|}
\hline \multirow[b]{2}{*}{ Agricult. } & \multicolumn{5}{|c|}{ N_America C_America S_America V } & \multirow{2}{*}{$\begin{array}{c}\text { MENA } \\
734730\end{array}$} & \multirow{2}{*}{\begin{tabular}{r|} 
Sahel \\
608258
\end{tabular}} & \multirow{2}{*}{$\begin{array}{r}\text { C_Africa } \\
844452\end{array}$} & \multirow{2}{*}{$\begin{array}{c}\text { S_Africa } \\
426322\end{array}$} & \multirow{2}{*}{$\begin{array}{c}\text { C_Asia } \\
303315\end{array}$} & \multirow{2}{*}{$\frac{|c| c i a}{2311110}$} & \multirow{2}{*}{$\frac{\text { S_Asia }}{2731888}$} & \multicolumn{2}{|c|}{ SE_Asia Australasia } \\
\hline & 1547014 & 616110 & 1298749 & 402202 & 1124436 & & & & & & & & 1727691 & 247796 \\
\hline \multirow{3}{*}{ [ndustrial } & $17.18 \%$ & $33.17 \%$ & $35.76 \%$ & $11.69 \%$ & $34.04 \%$ & $37.65 \%$ & $76.22 \%$ & $70.11 \%$ & $54.46 \%$ & $57.41 \%$ & $72.28 \%$ & $62.22 \%$ & $65.68 \%$ & $35.67 \%$ \\
\hline & 780162 & 191071 & 361737 & 265628 & $6151 C$ & 843983 & 14311 & 99705 & 12172 & 104673 & 6884 & 257745 & 243620 & 31479 \\
\hline & $53.09 \%$ & $54.91 \%$ & $109.53 \%$ & $54.30 \%$ & $69.17 \%$ & $65.83 \%$ & $23.62 \%$ & $113.44 \%$ & $110.15 \%$ & $115.36 \%$ & $128.10 \%$ & $131.22 \%$ & $118.73 \%$ & $7.08 \%$ \\
\hline \multirow[t]{2}{*}{ Municipal } & 65660 & 59006 & 43494 & 25683 & 57253 & 82789 & 21782 & 24977 & 32240 & 23383 & 395768 & 285798 & 105966 & 3831 \\
\hline & $69.77 \%$ & 31.03\% & $144.43 \%$ & $58.04 \%$ & $99.53 \%$ & $82.99 \%$ & $81.26 \%$ & $665.38 \%$ & $428.69 \%$ & $347.24 \%$ & $393.96 \%$ & $348.26 \%$ & $337.60 \%$ & $138.67 \%$ \\
\hline \multirow[t]{2}{*}{ otal } & 2392836 & 866187 & 1703980 & 693512 & 1796792 & 1661501 & 644352 & 979134 & 580289 & 431370 & 3395300 & 3275431 & 2077277 & 283107 \\
\hline & $28.07 \%$ & $41.64 \%$ & $48.54 \%$ & $26.43 \%$ & $.94 \%$ & $55.00 \%$ & $81.84 \%$ & $77.67 \%$ & $70.65 \%$ & $74.99 \%$ & $97.01 \%$ & $76.16 \%$ & $76.28 \%$ & $40.13 \%$ \\
\hline 11.0 & $42.88 \%$ & $9.98 \%$ & 6.41\% & $57.58 \%$ & $9.45 \%$ & $4.67 \%$ & $0.78 \%$ & $0 \%$ & $0 \%$ & $4.73 \%$ & $\%$ & $75.79 \%$ & $51.44 \%$ & $00.67 \%$ \\
\hline
\end{tabular}

2100 SSP1

N_America C_America S_America W_Europe E_Europe MENA Sahel C_Africa S_Africa $\quad$ C_Asia E_Asia S_Asia SE_Asia Australasia \begin{tabular}{r|r|r|r|r|r|r|r|r|r|r|r|r|r|r|}
\hline Agricult. & 1747743 & 693596 & 1449402 & 450766 & 1187242 & 830971 & 947263 & 1222214 & 629843 & 328225 & 2128853 & 3284692 & 2058588 & 287668 \\
\cline { 2 - 12 }
\end{tabular}

\begin{tabular}{|c|c|c|c|c|c|c|c|c|c|c|c|c|c|c|}
\hline \multirow{3}{*}{ Industrial } & $32.39 \%$ & $49.91 \%$ & $51.50 \%$ & $25.17 \%$ & $41.52 \%$ & $55.68 \%$ & $174.44 \%$ & $146.20 \%$ & $128.19 \%$ & $70.34 \%$ & $58.70 \%$ & $95.04 \%$ & $97.41 \%$ & $57.50 \%$ \\
\hline & 1333264 & 273039 & 654220 & 454036 & 878907 & 1181879 & 31135 & 211470 & 265371 & 159230 & 882510 & 481015 & 419143 & 53274 \\
\hline & $161.63 \%$ & $1.36 \%$ & $88.95 \%$ & $3.74 \%$ & $141.73 \%$ & $132.23 \%$ & $386.49 \%$ & $311.44 \%$ & $358.13 \%$ & $27.61 \%$ & $192.41 \%$ & $331.51 \%$ & $276.33 \%$ & 99.68\% \\
\hline \multirow[t]{2}{*}{ Municipal } & 85075 & 80685 & 54438 & 1884 & 63922 & $1587 \mid$ & 103995 & 100349 & 149064 & 30498 & 301933 & 521091 & 174747 & 5049 \\
\hline & $119.97 \%$ & $215.91 \%$ & $205.94 \%$ & $96.21 \%$ & $122.77 \%$ & $281.42 \%$ & $629.95 \%$ & $2975.05 \%$ & $344.44 \%$ & $483.34 \%$ & $276.84 \%$ & $717.31 \%$ & $621.64 \%$ & $214.52 \%$ \\
\hline \multirow[t]{2}{*}{ otal } & 3166083 & 1047320 & 2158060 & 936686 & 2130071 & 2124437 & 1082393 & 1534032 & 1044277 & 517953 & 3313296 & 4286797 & 2652478 & 345991 \\
\hline & $69.45 \%$ & $71.26 \%$ & $88.13 \%$ & $70.77 \%$ & $73.01 \%$ & $98.18 \%$ & $205.46 \%$ & $178.37 \%$ & $207.11 \%$ & $110.11 \%$ & $92.26 \%$ & $130.56 \%$ & $125.09 \%$ & $71.26 \%$ \\
\hline & 334 & $897.57 \%$ & $869.69 \%$ & $0.11 \%$ & $603.08 \%$ & $52 \%$ & $1.25 \%$ & $\%$ & $68 \%$ & 40 & & & $10 \%$ & \\
\hline
\end{tabular}

2050 SSP3

\begin{tabular}{|c|c|c|c|c|c|c|c|c|c|c|c|c|c|c|}
\hline \multirow[b]{2}{*}{ Agricult. } & \multicolumn{5}{|c|}{ N_America C_America } & \multirow{2}{*}{$\begin{array}{l}\text { MENA } \\
716348\end{array}$} & \multirow{2}{*}{$\begin{array}{r}\text { Sahel } \\
545526\end{array}$} & \multirow{2}{*}{$\begin{array}{r}\text { C_Africa } \\
779669\end{array}$} & \multirow{2}{*}{$\begin{array}{r}\text { S_Africa } \\
388527\end{array}$} & \multirow{2}{*}{$\begin{array}{c}\text { C_Asia } \\
299224\end{array}$} & \multirow{2}{*}{$\begin{array}{r}\text { E_Asia } \\
2173339\end{array}$} & \multirow{2}{*}{$\begin{array}{r}\text { S_Asia } \\
2525001\end{array}$} & \multicolumn{2}{|c|}{ SE_Asia Australasia } \\
\hline & 1460472 & 608690 & 1255468 & 361450 & 1077592 & & & & & & & & 1595920 & 219603 \\
\hline \multirow{3}{*}{ idustrial } & $10.63 \%$ & $31.56 \%$ & $31.23 \%$ & $0.37 \%$ & $28.45 \%$ & $34.20 \%$ & $58.05 \%$ & $57.06 \%$ & $40.76 \%$ & $55.29 \%$ & $62.01 \%$ & $49.93 \%$ & $53.04 \%$ & $20.23 \%$ \\
\hline & 727585 & 185823 & 344083 & 233334 & 582593 & 799859 & 12012 & 95850 & 104247 & 101814 & 641780 & 232423 & 221584 & 27483 \\
\hline & $42.78 \%$ & $50.65 \%$ & $99.30 \%$ & $35.54 \%$ & $60.23 \%$ & $57.16 \%$ & $87.68 \%$ & $86.49 \%$ & $79.97 \%$ & $109.48 \%$ & $112.65 \%$ & $108.50 \%$ & $98.95 \%$ & $54.60 \%$ \\
\hline \multirow[t]{2}{*}{ Iunicipal } & 50095 & 60480 & 41939 & 17899 & 48770 & 76964 & 13269 & 16463 & 21253 & 21887 & 292409 & 202855 & 77095 & 2620 \\
\hline & $29.52 \%$ & $36.80 \%$ & $135.69 \%$ & $10.15 \%$ & $69.96 \%$ & $63.08 \%$ & $75.93 \%$ & $404.50 \%$ & $248.51 \%$ & $318.62 \%$ & $264.96 \%$ & $218.17 \%$ & $218.38 \%$ & $63.22 \%$ \\
\hline \multirow[t]{2}{*}{ otal } & 2238151 & 854993 & 1641490 & 612683 & 1708956 & 1593171 & 570807 & 891983 & 514027 & 422924 & 3107528 & 2960278 & 1894600 & 249706 \\
\hline & $19.79 \%$ & $39.81 \%$ & $43.10 \%$ & $11.70 \%$ & $38.81 \%$ & $48.62 \%$ & $61.09 \%$ & $61.86 \%$ & $51.17 \%$ & $71.56 \%$ & $80.32 \%$ & $59.21 \%$ & $60.78 \%$ & $23.60 \%$ \\
\hline 10 & $73.44 \%$ & $308.59 \%$ & $31.47 \%$ & $49.09 \%$ & $267.02 \%$ & $347.84 \%$ & $30.60 \%$ & $955.50 \%$ & $568.12 \%$ & $020.51 \%$ & $953.98 \%$ & $644.31 \%$ & $669.92 \%$ & $133.21 \%$ \\
\hline
\end{tabular}

2100 SSP3

N_America C_America S_America W_Europe E_Europe $\quad$ MENA Sahel C_Africa S_Africa $\quad$ C_Asia E_Asia S_Asia SE_Asia Australasia

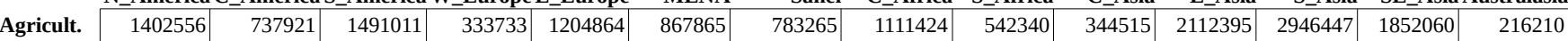

\begin{tabular}{|c|c|c|c|c|c|c|c|c|c|c|c|c|c|c|}
\hline \multirow{3}{*}{ lustri } & $6.24 \%$ & $59.49 \%$ & $55.85 \%$ & $-7.33 \%$ & $43.62 \%$ & $62.59 \%$ & $126.93 \%$ & $123.89 \%$ & $96.49 \%$ & $78.80 \%$ & $57.47 \%$ & $74.96 \%$ & $77.60 \%$ & $18.38 \%$ \\
\hline & 1017137 & 278457 & 656035 & 326761 & 868805 & 1165540 & 22304 & 172563 & 202468 & 160781 & 855374 & 404376 & 361988 & 37664 \\
\hline & $99.60 \%$ & $5.76 \%$ & $30.00 \%$ & $89.81 \%$ & $138.95 \%$ & $129.02 \%$ & $88.51 \%$ & $35.74 \%$ & $49.53 \%$ & $230.80 \%$ & $183.42 \%$ & $262.76 \%$ & $225.01 \%$ & $11.87 \%$ \\
\hline \multirow[t]{2}{*}{ unicipal } & 43144 & 96541 & 62444 & 14809 & 62063 & 120288 & 35161 & 46656 & 56783 & 32374 & 250046 & 294545 & 108890 & 2263 \\
\hline & $11.55 \%$ & $278.00 \%$ & $250.93 \%$ & $-8.87 \%$ & $116.29 \%$ & $311.17 \%$ & $161.10 \%$ & $329.70 \%$ & $831.16 \%$ & $519.22 \%$ & $212.08 \%$ & $361.98 \%$ & $349.68 \%$ & $40.94 \%$ \\
\hline & 2462836 & 1112919 & 2209490 & 675303 & 2135732 & 2153693 & 840730 & 1330642 & 801590 & 537670 & 3217816 & 3645368 & 2322938 & 256137 \\
\hline & $31.81 \%$ & $81.98 \%$ & $92.61 \%$ & $23.11 \%$ & $73.47 \%$ & $100.91 \%$ & $137.26 \%$ & $141.46 \%$ & $135.74 \%$ & $118.11 \%$ & $86.71 \%$ & $96.06 \%$ & $97.13 \%$ & $26.78 \%$ \\
\hline & $82.57 \%$ & $793.82 \%$ & $748.21 \%$ & $63.51 \%$ & $494.36 \%$ & $847.50 \%$ & $3632.63 \%$ & $4317.64 \%$ & $2726.50 \%$ & $1944.13 \%$ & $937.64 \%$ & $293.47 \%$ & $1292.11 \%$ & $146.53 \%$ \\
\hline
\end{tabular}


Estimates of industrial output are especially relevant here because, coupled with our calculated water intensity coefficients, they allow us to derive the implied water demand for the years 2050 and 2100. Analogously, municipal water demand was computed by assuming it dependent on population growth, real income levels and a trend of increased water efficiency ${ }^{13}$.

The first-round projections which are used as a baseline for future comparisons of water demand are displayed in Table 3. The Table also reports the corresponding variations in regional GDP obtained from the SSPs ${ }^{14}$. Water demand estimates do not take account of possible efficiency gains in addition to those observed historically, or alternative policy responses. These are issues we turn to in the next sections of this paper.

\section{The effect of water availability constraints}

The logical next step in the analysis is to compare future water demand with climate impacted supplies and to assess the economic consequences of any emerging water deficits. However, the concept of water supply cannot be unambiguously defined because, for instance, water quality is variable, and water is transformed rather than consumed (the water cycle). Furthermore, our analysis is affected by aggregation issues, as we deal with large macro-regions in periods of one year, whereas the matching between water demand and supply occurs at a much finer spatial-temporal scale.

For our purposes, we define "sustainable water supply" the sum of water runoff and inflow in a region ${ }^{15}$, in line with the definition of the Water Scarcity Index (WSI) used in the literature (e.g., World Bank, 2015). The reason for focusing on runoff and inflow is that it captures most hydrological sources that impact water supply (e.g., groundwater, through aquifer replenishment). Further we allow for so-called "unconventional” water management options (e.g., desalination, harvesting, recycling) through changes in water efficiency. On the other hand unsustainable abstraction of ground or surface water is ruled out as it is not a feasible long run strategy.

Our assessment of future water availability is based on the GCAM model ${ }^{16}$. The GCAM model has been used to estimate water runoffs and inflows on the basis of exogenous climate variables provided by three different Global Circulation Models (CCSM, GISS, FIO ESM). Figure 2 shows the estimated global runoff generation (sum for all countries) for the three GCMs covering wet, medium and dry model outcomes in the GCAM ensemble.

13 More precisely, the variation in municipal water demand $(m)$ is formulated as $m=(p+0.35 y) f$. Where $p$ is the percentage change of regional population, $y$ stands for real income change, $f$ is an efficiency factor equal to 0.8 in 2050 and 0.7 in 2100 . The 0.35 elasticity value is taken from Worthington and Hoffman (2006).

14 Some variations may look implausibly large. However, a +3000\% variation in the period 2004-2100 corresponds to a $+3.64 \%$ average yearly change, $+2000 \%$ to $+3.22 \%$, $+1000 \%$ to $+2.53 \%$. A $+15000 \%$ variation corresponds to $+5.37 \%$.

15 As we use rather large macro-regions in this study, the amount of water inflow is normally negligible, with one exception: the inflow of the Nile river for the Middle East and North Africa (MENA) region.

16 http://www.globalchange.umd.edu/models/gcam . 


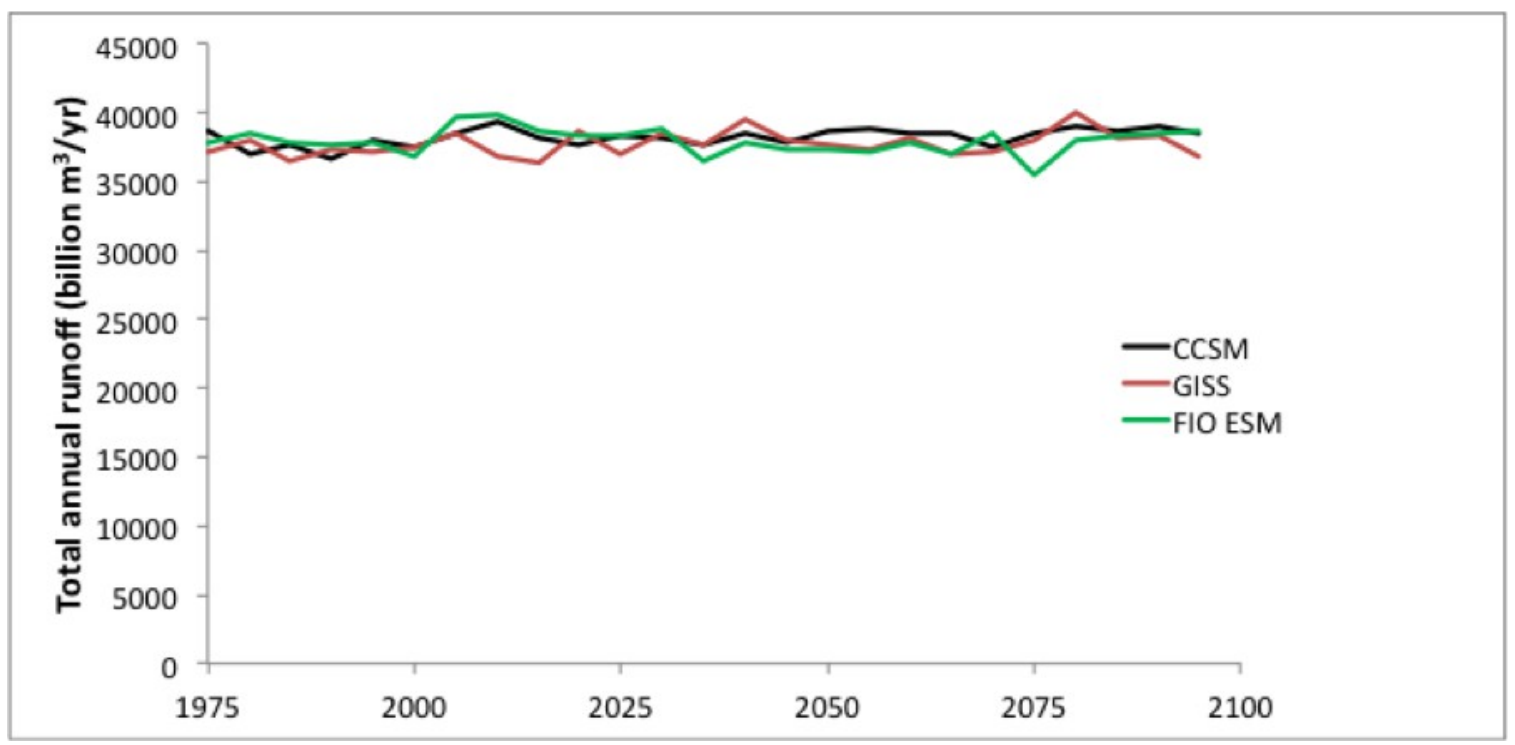

Figure 2 - Estimated global runoff

It is immediately evident that, although some differences between the three cases exist (especially at the regional level, not shown here), the overall availability of water resources is not expected to change in any significant way during the century, reflecting the fact that the water cycle is closed. On the other hand, to the extent that the demand for water follows regional economic and demographic growth, increasing pressure on limited water resources emerges in several areas.

To gauge the severity of this pressure the mean estimate of "sustainable water supply", obtained as mathematical averages of the three regional runoffs and inflows estimates, is compared with our projections of water demand. Tables 4 and 5 display the percentage of excess of potential water demand for the two scenarios (SSP1 and SSP2) and the two reference years 2050 and 2100. In other words, it shows, ceteris paribus, the amount of reduction in water demand that would be necessary to make it sustainable and compatible with the actual availability of renewable water resources.

The differences in the qualitative pictures emerging from the two socio-economic scenarios SSP1 and SSP3 are minor. On the other hand the regional disparities are vast. Current water consumption already exceeds sustainable levels in some regions, most notably in the Middle East and North Africa (MENA) but also in South Asia (India and neighbor countries). Things get worse over the century, with more regions experiencing tightening water scarcity, all located in Africa and Asia. 
Table 4 - Percentage excess demand for water (SSP1)

GAP \%
\begin{tabular}{|l|r|r|r|}
\hline 1 N_America & 0.0 & 0.0 & 0.0 \\
\hline 2 C_America & 0.0 & 0.0 & 0.0 \\
\hline 3 S_America & 0.0 & 0.0 & 0.0 \\
\hline 4 W_Europe & 0.0 & 0.0 & 0.0 \\
\hline 5 E_Europe & 0.0 & 0.0 & 0.0 \\
\hline 6 MENA & -53.5 & -76.4 & -83.0 \\
\hline 7 Sahel & 0.0 & 0.0 & -11.9 \\
\hline 8 C_Africa & 0.0 & 0.0 & 0.0 \\
\hline 9 S_Africa & 0.0 & 0.0 & 0.0 \\
\hline 10 C_Asia & 0.0 & 0.0 & -20.2 \\
\hline 11 E_Asia & 0.0 & -31.7 & -31.1 \\
\hline 12 S_Asia & -8.7 & -47.8 & -58.2 \\
\hline 13 SE_Asia & 0.0 & 0.0 & 0.0 \\
\hline 14 Australasia & 0.0 & 0.0 & 0.0 \\
\hline
\end{tabular}

How could the excessive demand for water be reconciled with future water availability? We consider three complementary strategies that are commonly observed - technology change, policy induced allocation changes (i.e., a substitution effect) and an output effect:

- Technology effects. With water becoming scarcer and more valued, technical efficiency measures could be adopted. Moreover scarcity would render investments in water saving technologies more attractive and viable. Technical efficiency measures might include: modern irrigation systems, water harvesting and recycling, desalination, use of brackish water in agriculture;

- Substitution effects. Water would likely be allocated in a more efficient fashion in time and space. Water storage basins, for instance, could smooth the mismatch between precipitation and usage time. Economic activities demanding relatively more water would be allocated in subregions in which water is not scarce (recall that the model involves very large macro-regions with differentiated conditions);

- $\quad$ Output effects. Finally, water scarcity could impair some economic activities, and in a CGE setup the market would curb the indirect demand for water, by acting on its primary determinants. For example, with less water available for irrigation, lower crop productivity would be experienced in agriculture. The latter would increase the price of domestic products and reduce output volumes, ultimately reducing the demand for irrigation water as well. 
Table 5 - Percentage excess demand for water (SSP3)

GAP \%
\begin{tabular}{|l|r|r|r|}
\hline 1 N_America & 0.0 & 0.0 & 0.0 \\
\hline 2 C_America & 0.0 & 0.0 & 0.0 \\
\hline 3 S_America & 0.0 & 0.0 & 0.0 \\
\hline 4 W_Europe & 0.0 & 0.0 & 0.0 \\
\hline 5 E_Europe & 0.0 & 0.0 & 0.0 \\
\hline 6 MENA & -53.5 & -75.3 & -83.2 \\
\hline 7 Sahel & 0.0 & 0.0 & 0.0 \\
\hline 8 C_Africa & 0.0 & 0.0 & 0.0 \\
\hline 9 S_Africa & 0.0 & 0.0 & 0.0 \\
\hline 10 C_Asia & 0.0 & 0.0 & -23.1 \\
\hline 11 E_Asia & 0.0 & -25.3 & -29.1 \\
\hline 12 S_Asia & -8.7 & -42.2 & -50.8 \\
\hline 13 SE_Asia & 0.0 & 0.0 & 0.0 \\
\hline 14 Australasia & 0.0 & 0.0 & 0.0 \\
\hline
\end{tabular}

Drawing upon the regression estimates described in Section 3, it is assumed that much of the demandsupply gap can be covered by direct and indirect efficiency improvements. More precisely a $100 \%$ increase in output triggers on average a 25\% drop in (multi-factor) productivity (production volumes) for the water demanding industries ceteris paribus. This hypothesis is based on estimates informed by the regression analysis and may not hold uniformly. Hence in the Appendix results of a comprehensive sensitivity analysis are provided, where both the water supply and the share covered through changes in productivity are considered as random variables. Our central results seem robust to these experiments over large ranges.

The magnitude of the industrial productivity cuts depends, in principle, on the amount of water allocated to each industry. We consider a simple baseline, in which water is reduced proportionally in all water demanding industries, with variations in output approximately of same amount, triggered by changes in productivity ${ }^{17}$. We contrast this baseline case (no inter-industrial water reallocation [NOWR]) with two alternative policy options. Recognizing that perfect reallocations are improbable and unrealistic, smaller reductions are applied in sectors where water is relatively more valuable (and vice versa). We consider mild [MILD] and strong [STRONG] water reallocation schemes. ${ }^{18}$ These scenarios may be viewed as proxies for a water market.

The economic implications of the three scenarios are evaluated by means of a global Computable General Equilibrium model, using a version of the GTAP model, described in Hertel and Tsigas (1997).

17 We change the productivity factors in such a way that output would fall by the same percentage of the water cut, if all other variables in the general equilibrium model would stay fixed. However, once these other variables are endogenously varied in a simulation experiment, the actual change in output will be different.

18 The inverse of the water intensity coefficient is the value of production per unit of water, that is, the water industrial productivity. We allocate water (therefore, cuts in productivity) at the industrial level through a function, which depends on relative water returns. An elasticity parameter affects the sensitivity to the relative returns, and this is set to 0.1 for the MILD scenario, 0.25 for the STRONG scenario. With a strong inter-industrial allocation of water, it turns out that a few industries, where water is quite valuable, can get more water than in the baseline (despite the fact that water consumption is reduced for the macro-region as a whole). In this case, they increase their productivity and production volumes. 
A CGE model is a very large non-linear system, providing a disaggregated representation of national, regional and multi-regional economies. The system includes market clearing conditions and accounting identities, to trace the circular flow of income and inter-sectoral linkages inside the economic system, and simulations are performed as comparative statics exercises. This means that two hypothetical equilibria are compared: a baseline reference and a perturbed equilibrium, in which the structural adjustment processes triggered by parameter changes are simulated. The exogenous variables which have been varied in our simulation exercises are the industrial multi-factor productivity parameters, as described above.

Table 6 - Percentage variation in real GDP (SSP1, 2050)

\begin{tabular}{|l|r|r|r|}
\hline \multicolumn{1}{|c}{ NO-WR MILD STRONG } \\
\hline 1 N_America & -0.01 & -0.01 & 0 \\
\hline 2 C_America & 0.07 & 0.08 & 0.1 \\
\hline 3 S_America & -0.02 & -0.01 & 0 \\
\hline 4 W_Europe & -0.01 & -0.01 & -0.01 \\
\hline 5 E_Europe & 0.07 & 0.07 & 0.06 \\
\hline 6 MENA & -12.22 & -9.04 & -4.63 \\
\hline 7 Sahel & 0.2 & 0.36 & 0.75 \\
\hline 8 C_Africa & 0.39 & 0.41 & 0.47 \\
\hline 9 S_Africa & -0.04 & -0.01 & 0.07 \\
\hline 10 C_Asia & 0.13 & 0.13 & 0.13 \\
\hline 11 E_Asia & -2.81 & -1.78 & 1.16 \\
\hline 12 S_Asia & -5.96 & -5.27 & 1.12 \\
\hline 13 SE_Asia & -0.02 & -0.02 & 0 \\
\hline 14 Australasia & -0.02 & -0.01 & 0.02 \\
\hline WORLD & -0.19 & -0.13 & 0.01 \\
\hline
\end{tabular}

Table 7 - Percentage variation in real GDP (SSP3, 2050)

\begin{tabular}{|l|r|r|r|}
\hline \multicolumn{1}{|c}{ NO-WR MILD STRONG } \\
\hline 1 N_America & -0.01 & -0.01 & 0 \\
\hline 2 C_America & 0.06 & 0.07 & 0.1 \\
\hline 3 S_America & -0.01 & 0 & 0 \\
\hline 4 W_Europe & 0 & 0 & 0 \\
\hline 5 E_Europe & 0.05 & 0.04 & 0.06 \\
\hline 6 MENA & -11.77 & -8.67 & -3.37 \\
\hline 7 Sahel & 0.09 & 0.18 & 0.31 \\
\hline 8 C_Africa & 0.25 & 0.27 & 0.35 \\
\hline 9 S_Africa & -0.02 & 0 & 0.05 \\
\hline 10 C_Asia & 0.11 & 0.13 & 0.16 \\
\hline 11 E_Asia & -2.23 & -1.42 & 0.93 \\
\hline 12 S_Asia & -4.93 & -3.87 & 1.15 \\
\hline 13 SE_Asia & -0.01 & -0.01 & 0.01 \\
\hline 14 Australasia & -0.01 & 0 & 0.02 \\
\hline WORLD & -0.24 & -0.17 & 0.02 \\
\hline
\end{tabular}


The output of a CGE simulation is very rich and includes information on: income, consumption levels, welfare, international trade, prices and production volumes. We illustrate here the impact of water scarcity and agricultural productivity, under the various scenarios, on a few key macroeconomic indicators. Tables 6 and 7 shows the computed percentage variation in the real Gross Domestic Product (GDP) for SSP1 and SSP3, respectively, at the year 2050.

Effects on real aggregate income are dramatic in some regions (MENA, S_Asia) if water is reduced uniformly across industries, and the impact is sizable even at the global level. However, these negative effects can be significantly curbed if some reallocation of scarce water resources takes place. If the water reallocation is marked (STRONG), we find that the macroeconomic impact of water scarcity becomes positive for regions in Asia and for the world as a whole. This is because the lack of water resources is more than compensated by a relatively more efficient distribution of economic activities, benefitting those industries which do not consume water, or in which the implicit returns on water are higher. Again, there are no significant differences between SSP1 and SSP3, from a qualitative point of view, although global variations are larger in SSP3.

Table 8 - Equivalent Variation (millions US\$, SSP1, 2050)

\begin{tabular}{|l|r|r|r|}
\hline \multicolumn{1}{c}{} & NO-WR & MILD & STRONG \\
\hline 1 N_America & -11768 & -8068 & 1292 \\
\hline 2 C_America & 1220 & 1464 & 2151 \\
\hline 3 S_America & 1469 & 1564 & 1781 \\
\hline 4 W_Europe & -13446 & -9954 & -1080 \\
\hline 5 E_Europe & 2668 & 2633 & 2624 \\
\hline 6 MENA & -152712 & -108448 & -45528 \\
\hline 7 Sahel & 822 & 1054 & 1570 \\
\hline 8 C_Africa & 10796 & 10548 & 10271 \\
\hline 9 S_Africa & 1309 & 1428 & 1701 \\
\hline 10 C_Asia & 1381 & 1430 & 1496 \\
\hline 11 E_Asia & -196536 & -131264 & 56480 \\
\hline 12 S_Asia & -42196 & -36073 & 10208 \\
\hline 13 SE_Asia & 3326 & 3334 & 3545 \\
\hline 14 Australasia & 513 & 806 & 1516 \\
\hline WORLD & -393154 & -269546 & 48026 \\
\hline
\end{tabular}

Tables 8 and 9 illustrates the aggregate effects in terms of Equivalent Variation (EV). The EV is the variation in domestic income which would be considered "welfare equivalent" in a situation after the climate induced change in prices, quantities and income obtained as a counterfactual solution of the general equilibrium model. In other words, it is a "virtual price" that the various regions are supposed to pay as a consequence of future water scarcity. The EV provides an indication of the change in income necessary to produce the reference levels of well-being. It is thus a theoretically more accurate measure of welfare loss than changes in GDP. The Table provides absolute values. Therefore, even if the relative variation of the GDP is largest for MENA in the NO-WR simulations, the highest price, in absolute terms, is virtually paid by East Asia, suggesting that the welfare loss (change) is greatest in East Asia. 
Table 9 - Equivalent Variation (millions US\$, SSP3, 2050)

\begin{tabular}{|l|r|r|r|}
\hline \multicolumn{1}{l}{ NO-WR } & MILD & STRONG \\
\hline 1 N_America & -8813 & -5988 & 772 \\
\hline 2 C_America & 1318 & 1548 & 2233 \\
\hline 3 S_America & 1702 & 1807 & 1218 \\
\hline 4 W_Europe & -9973 & -7435 & 734 \\
\hline 5 E_Europe & 2454 & 2445 & 2652 \\
\hline 6 MENA & -152123 & -107905 & -34661 \\
\hline 7 Sahel & 391 & 542 & 642 \\
\hline 8 C_Africa & 6167 & 6250 & 6616 \\
\hline 9 S_Africa & 635 & 777 & 1040 \\
\hline 10 C_Asia & 1484 & 1588 & 1788 \\
\hline 11 E_Asia & -161896 & -109616 & 43272 \\
\hline 12 S_Asia & -38200 & -29282 & 9648 \\
\hline 13 SE_Asia & 2307 & 2362 & 2567 \\
\hline 14 Australasia & 412 & 672 & 1231 \\
\hline WORLD & -354136 & -242235 & 39751 \\
\hline
\end{tabular}

\section{Economic structure and virtual water trade}

The reduced water availability and the consequent change in industrial productivity bring about a structural change in all regional economies, as the relative competitiveness of the different industries varies. The effect goes beyond the industries and regions affected by the productivity shock. For example, when domestic agricultural products become more expensive to produce, because of water shortage, more imported agricultural products will be bought. To keep the payment balance in equilibrium, a real devaluation of the national currency will follow, making - ceteris paribus - the domestic manufacturing sector or, more generally, the non-water-consuming industries relatively more competitive in the international markets.

To illustrate how the economic structure would change under the different conditions, we take the physical output of industries in the MENA region, for the SSP1 scenario, as an example. Table 10 displays the percentage variation of output under the three policy options of water allocation.

We can see that, when water endowments are reduced by the same percentage in all sectors, production levels drop by different proportions, and the output falls even for those industries that do not employ water in their production processes (despite the real devaluation effect explained above). This may be due to a combination of factors, including lower domestic income (reducing the internal final demand) and more expensive (domestic) intermediate factors.

However, when the reduced water stock is assigned to the different sectors and the relative returns on water are considered, we see that some industries (mainly in agriculture) shrink even more, but others reduce much less or even increase their production volumes. Of course, this rebalancing effect is more noticeable when the water reallocation scheme is "strong”. 
Table 10 - Percentage Variation in Industry Output (MENA, SSP1, 2050)

\begin{tabular}{|l|r|r|r|}
\multicolumn{1}{c}{ NO-WR MILD STRONG } \\
\hline Rice & -25.67 & -30.85 & -56.52 \\
\hline Wheat & -14.34 & -18.14 & -34 \\
\hline Cereals & -7.48 & -8.53 & -14.59 \\
\hline VegetFruits & -7.93 & -8.13 & -10.91 \\
\hline OilSeeds & -13.91 & -16.66 & -28.9 \\
\hline Sugar & -7.62 & -5.36 & -2.95 \\
\hline Fibers & -10.81 & -8.48 & -5.89 \\
\hline OtherCrops & -17.42 & -21.36 & -38.55 \\
\hline MeatLstk & -2.42 & -2.35 & -4.56 \\
\hline Extraction & -26.39 & -23.35 & -19.85 \\
\hline ProcFood & -8.05 & -5.36 & -2.18 \\
\hline TextWapp & -10.34 & -1.35 & 12.44 \\
\hline LightMnfc & -31.53 & -11.72 & 20.28 \\
\hline HeavyMnfc & -18.1 & -10.05 & 3.65 \\
\hline Electricity & -11.97 & -7.7 & -1.06 \\
\hline Gas & -13.19 & -9.4 & -3.27 \\
\hline Water & -9.1 & -6.93 & -3.72 \\
\hline Construction & -4.35 & -2.94 & -0.56 \\
\hline TransComm & -2.69 & -1.74 & -0.13 \\
\hline OthServices & -1.81 & -1.41 & -0.79 \\
\hline
\end{tabular}

Another interesting way to look at the changes in the economic structure is analyzing the variations in virtual water trade flows. Virtual water trade refers to the implicit content of water in import and export flows. The water intensity coefficients can be employed to estimate the amount of water that was used to produce goods that have been subsequently transferred abroad, which can be interpreted as a virtual export of water. Table 11 presents the changes in virtual water flows (in millions $\mathrm{m}^{3}$ ) among the 14 macro-regions, for SSP1/2050/NO-WR.

Table 11 - Changes in virtual water trade flows (SSP1, 2050, NO-WR)

\begin{tabular}{|l|r|r|r|r|r|r|r|r|r|r|r|r|r|r|r|}
\hline From $\backslash$ To & N_Am & C_Am & S_Am & W_Eu & E_Eu & MENA & Sahel & C_Afr & S_Afr & C_Asia & E_Asia & S_Asia & SE_Asia & Austr & Tot. \\
\hline N_Am & 0 & 367 & 95 & 403 & 27 & 921 & 18 & 203 & 57 & 2 & 2092 & 71 & 257 & 23 & $\mathbf{4 5 3 6}$ \\
\hline C_Am & 1254 & 0 & 27 & 368 & 21 & 107 & 0 & 2 & 2 & 0 & 285 & 130 & 15 & 2 & $\mathbf{2 2 1 3}$ \\
\hline S_Am & 220 & 11 & 0 & 583 & 197 & 553 & 0 & 69 & 32 & 12 & 953 & 37 & 74 & 7 & $\mathbf{2 7 4 8}$ \\
\hline W_Eu & 81 & 6 & 6 & 0 & 87 & 316 & 13 & 29 & 36 & 2 & 175 & 222 & 36 & 3 & $\mathbf{1 0 1 0}$ \\
\hline E_Eu & 54 & 2 & 12 & 764 & 0 & 1805 & 2 & 18 & 25 & 13 & 1365 & 38 & 166 & 2 & $\mathbf{4 2 6 6}$ \\
\hline MENA & -1603 & -75 & -180 & -3943 & -393 & 0 & -14 & -82 & -474 & -17 & -13141 & -1646 & -2110 & -99 & $\mathbf{- 2 3 7 7 8}$ \\
\hline Sahel & 6 & -6 & -1 & -10 & 1 & -70 & 0 & 79 & 11 & 0 & -10 & 47 & 179 & 1 & $\mathbf{2 2 8}$ \\
\hline C_Afr & -219 & -15 & -42 & -318 & -12 & 1 & -4 & 0 & 23 & 0 & 293 & 110 & 41 & -1 & $\mathbf{- 1 4 5}$ \\
\hline S_Afr & -6 & -3 & -1 & 101 & 12 & 135 & 1 & 22 & 0 & 0 & 606 & 17 & 97 & 1 & $\mathbf{9 8 2}$ \\
\hline C_Asia & 9 & -4 & -3 & 116 & 34 & 284 & 0 & 0 & 1 & 0 & 95 & 8 & 9 & 0 & $\mathbf{5 5 0}$ \\
\hline E_Asia & -176 & -17 & -4 & -192 & -26 & -18 & -1 & 4 & 0 & 1 & 0 & 6 & 46 & -5 & $\mathbf{- 3 8 1}$ \\
\hline S_Asia & -1005 & -192 & -49 & -1582 & -139 & 860 & -26 & -310 & -136 & -9 & -1297 & 0 & -678 & -50 & $\mathbf{- 4 6 1 5}$ \\
\hline SE_Asia & 61 & 10 & 11 & 224 & 54 & 1875 & 16 & 101 & 48 & 2 & 1489 & 188 & 0 & 36 & $\mathbf{4 1 1 4}$ \\
\hline Austr & 12 & -1 & 1 & 6 & 1 & 266 & -1 & 19 & 29 & 0 & 158 & 44 & 259 & 0 & $\mathbf{7 9 4}$ \\
\hline Tot. & $\mathbf{- 1 3 1 2}$ & $\mathbf{8 2}$ & $\mathbf{- 1 2 9}$ & $\mathbf{- 3 4 8 0}$ & $\mathbf{- 1 3 5}$ & $\mathbf{7 0 3 5}$ & $\mathbf{3}$ & $\mathbf{1 5 4}$ & $\mathbf{- 3 4 6}$ & $\mathbf{5}$ & $\mathbf{- 6 9 3 7}$ & $\mathbf{- 7 2 8}$ & $\mathbf{- 1 6 1 0}$ & $\mathbf{- 8 1}$ & \\
\hline
\end{tabular}

The reduction in agricultural production and other water consuming activities in water constrained regions implies a substitution of domestic water-consuming goods with imports, that is an increase of virtual water imports. The difference between row and column totals gives the changes in the "virtual 
water trade balance”. For instance it is found that, as a consequence of the market mechanisms affecting the economic structure, MENA increases its net imports of virtual water of about 30.8 billions of $\mathrm{m}^{3}$. This can be considered a market-mediated response to the emerging water scarcity. South Asia (another water-constrained region) also increases its net imports of virtual water (3.9 billions of $\left.\mathrm{m}^{3}\right)^{19}$. Of course, other regions expand their net exports, because the change in the global virtual water trade balance must be zero.

\section{Concluding remarks}

In this paper the results of some numerical simulation exercises aimed at assessing the macroeconomic consequences of a possible future scarcity of water have been presented. As with all modeling exercises, the analysis is based upon a litany of assumptions and cannot be interpreted as predictions of future changes in GDP. Instead the exercise serves to improve understanding of the magnitude and direction of changes and how alternative policies can either accentuate or mitigate the adverse impacts.

The results demonstrate that water remains a significant obstacle to growth and development in some regions, in the context of a changing climate. It also forcefully illustrates that prudent management of water resources is likely sufficient to neutralize some of the undesirable impacts. Along the way several assumptions have been introduced, which are all more or less questionable. Nevertheless, the main results are robust to alternative conjectures as suggested by the simulations in the Appendix, and three main messages emerge from the analysis.

First, scenarios of economic development (the SSPs) that have been recently proposed to support the scientific analyses of climate change have ignored water availability. The underlying assumptions of sustained economic growth, especially for developing countries, would imply an excessive consumption of water, even when substantial improvements in water efficiency are envisaged. Our analysis shows that the baseline SSP growth scenarios are incompatible with the implied impacts on water supply.

Second, and related to the previous point, the emerging water scarcity will mainly affect developing countries in Africa and Asia, hampering their prospects of economic growth. This means that water scarcity will increase economic inequality around the world.

Third, an economically efficient reallocation of scarce water resources towards sectors where the economic return per unit of water is higher can be a very effective policy response to the emerging water scarcity and its consequences. The analysis reveals that with a STRONG reallocation of water (implying aggressive policies in many countries), would it be possible to mitigate the macroeconomic impacts (e.g., measured by GDP) due to water resources scarcity. Of course, the model says nothing about how this reallocation could be implemented in practice. The introduction of water markets (i.e. efficient water pricing) or a more market-oriented planning of water infrastructure could be part of the solution. These are issues that have been widely discussed in the water management literature and are beyond the scope of this modeling exercise.

19 However, East Asia reduces both its exports and imports of virtual water, but with a stronger reduction in exports, thereby improving its "virtual water trade balance". This case makes clear that adjustments in the virtual water trade flows are complex and several factors, affecting the final balance, are at play. 


\section{Appendix: a sensitivity analysis}

The results of our numerical exercise are affected by multiple uncertainties and one may wonder how robust our findings are with respect to baseline estimates and alternative assumptions. To partially respond to these concerns, we illustrate in this appendix a sensitivity analysis for the 2050 SSP1 scenario without inter-industrial water reallocation (NO-WR).

Simulations in the general equilibrium model are based on exogenous variations in industrial productivity, meant to reduce output volumes in each sector to a level compatible with water availability. The magnitude of these exogenous shocks depends on the gap between potential water demand and supply, as well as on the share of the gap covered by means of production cuts (we assumed 25\%). For example, if potential water demand exceeds supply by $50 \%$, then industrial output should be reduced by $8.33 \%$ (25\%*50\% / 150\%).

We have conducted a sensitivity analysis by allowing uncertainty in both the estimates of water supply and on the share of the gap covered through reductions in industrial output. More precisely, instead of fixing the water supply in each country at a given level, we interpret the water supply as a normally distributed random variable with mean equal to that level and standard deviation equal to $2.5 \%$ of it. This means that there is a $95 \%$ probability that the actual level of water supply falls inside the $+/-4.9 \%$ range of our initial estimate. Analogously, the gap share is assumed to be a (truncated) normally distributed random variable, with mean $25 \%$ and standard error $12.5 \%$ (confidence interval $0.5 \%$ $49.5 \%)$.

Since the exogenous shocks in the CGE model are obtained by a function involving both water supply and gap shares, the shocks themselves become random variables ${ }^{20}$. A sensitivity analysis can then conducted by performing many simulation runs, where each run is driven by one specific realization of the multidimensional random variable of the shocks. Here, we have undertaken 100 simulation runs, getting 100 different values for all endogenous variables in the model. These results have subsequently been processed by means of statistical quadrature techniques, to infer the distribution of the endogenous variables.

Since we are assuming as a mean for the water supply and gap shares random variables the same values that were adopted in the deterministic model, it is not surprising that the central values estimated for the endogenous variables coincide with the values obtained beforehand. The additional information obtained by the sensitivity analysis is the dispersion of the distribution, measured for instance by its standard deviation. In turn, the standard deviation provides an assessment of the robustness of the results: the higher the standard deviation, the larger the uncertainty on the model output.

By way of illustration, Table A1 presents the estimates of real GDP deviations in the 2050/SSP1/NOWR sensitivity analysis. Three columns are shown. The one in the middle corresponds to the NO-WR column in Table 8, that is our best estimate of variations in real GDP for the scenario at hand. The left and right columns present the lower and upper bounds of the 95\% confidence interval for our estimates. Therefore, they identify an interval which is "very likely" to contain the "true" variation in real GDP. Of course, the same kind of analysis can be conducted for all other variables in the model.

20 These random variables are assumed to be stochastically independent and are approximated in the numerical analysis as triangular distributions with the same standard deviations as in the corresponding normal distributions. 
Table A1 - Percentage variation in Real GDP (SSP1, 2050)

with 95\% confidence interval

\begin{tabular}{|l|r|r|r|}
\multicolumn{1}{l}{} & \multicolumn{1}{c}{ min } & \multicolumn{1}{c}{$\begin{array}{c}\text { NO-wr } \\
\text { mean }\end{array}$} & \multicolumn{1}{l}{ max } \\
\hline 1 N_America & -0.01 & -0.01 & -0.01 \\
\hline 2 C_America & -0.03 & 0.07 & 0.17 \\
\hline 3 S_America & -0.02 & -0.02 & -0.02 \\
\hline 4 W_Europe & -0.01 & -0.01 & -0.01 \\
\hline 5 E_Europe & -0.03 & 0.07 & 0.17 \\
\hline 6 MENA & -17.41 & -12.22 & -7.11 \\
\hline 7 Sahel & -0.33 & 0.2 & 0.73 \\
\hline 8 C_Africa & -0.13 & 0.39 & 0.93 \\
\hline 9 S_Africa & -0.10 & -0.04 & 0.02 \\
\hline 10 C_Asia & -0.05 & 0.13 & 0.31 \\
\hline 11 E_Asia & -3.85 & -2.81 & -1.77 \\
\hline 12 S_Asia & -7.50 & -5.96 & -4.44 \\
\hline 13 SE_Asia & -0.06 & -0.02 & 0.02 \\
\hline 14 Australasia & -0.04 & -0.02 & 0.00 \\
\hline
\end{tabular}

\section{References}

Agrawala S. et al. (2011). "Plan or React? Analysis of adaptation costs and benefits using Integrated Assessment Models”, Climate Change Economics, Vol. 2(3), pp. 175-208.

Bosello F., F. Eboli and R. Pierfederici (2012), “Assessing the Economic Impacts of Climate Change. An Updated CGE Point of View”, FEEM Working Report, No. 2/12.

Bosello F., R. Roson and R.S.J. Tol (2006). "Economy wide estimates of the implications of climate change: human health”, Ecological Economics, Vol. 58, pp. 579-591.

Brown C., Meeks, R., Ghile, Y., and Hunu, K. (2013), “Is water security necessary? An empirical analysis of the effects of climate hazards on national level economic growth", Philosophical Transactions of the Royal Society, Vol. 371, pp. 1-19.

Calzadilla A., K. Rehdanz, R. Roson, M. Sartori and R. Tol (2016) "Review of CGE Models of Water Issues” in: A. Dinar (ed.) The WSPC Reference on Natural Resources and Environmental Policy in an Era of Global Change, Volume 3, T. Byant (ed.) Global Economic Models - CGE, World Scientific Publishing, forthcoming.

Damania R. and S. Dahan (2015) (eds.) The Forgotten Factor in Climate Change - Water, The World Bank, Washington D.C..

Dell M., B.F. Jones and B.A. Olken (2012), “Temperature Shocks and Economic Growth: Evidence from the Last Half Century”, American Economic Journal: Macroeconomics, Vol. 4(3), pp. 66-95.

Dietzenbacher E., Los, B., Stehrer, R., Timmer, M. and G. de Vries (2013), “The Construction of 
World Input-Output Tables in the WIOD Project”, Economic Systems Research, vol. 25, pp. 71-98.

Eboli F. , R. Parrado and R. Roson (2010), “Climate Change Feedback on Economic Growth: Explorations with a Dynamic General Equilibrium Model”, Environment and Development Economics, vol.15, pp.515-533.

Genty, A., Arto, I. and F. Neuwahl (2013), Final Database of Environmental Satellite Accounts: Technical Report on their Compilation, Available online: http://www.wiod.org/publications/source_docs/Environmental_Sources.pdf .

Hanasaki N., S. Fujimori, T. Yamamoto, S. Yoshikawa, Y. Masaki, Y. Hijioka, M. Kainuma, Y. Kanamori, T. Masui, K. Takahashi and S. Kanae (2013), “A global water scarcity assessment under Shared Socio-economic Pathways - Part 1: Water use”, Hydrology and Earth System Sciences, vol. 17, pp. 2375-2391.

Hertel, T.W. and Tsigas, M.E. (1997) “Structure of GTAP”, in: T.W. Hertel (ed.), Global Trade Analysis: Modeling and Applications, Cambridge University Press.

IPCC (2014), Climate Change 2014: Impacts, Adaptation, and Vulnerability. Part A: Global and Sectoral Aspects. Contribution of Working Group II to the Fifth Assessment Report of the Intergovernmental Panel on Climate Change, Cambridge University Press.

Kriegler E., B.C. O’Neill, S. Hallegatte, T. Kram, R.J. Lempert, R.H. Moss and T. Wilbanks (2012), "The need for and use of socio-economic scenarios for climate change analysis: A new approach based on shared socio-economic pathways”, Global Environmental Change, vol. 22, pp. 807-822.

Mekonnen, M. and A. Hoekstra (2011), National water footprint accounts: the green, blue and grey water footprint of production and consumption, Value of Water Research Report Series No.50, Volume I and II. UNESCO-IHE, Delft, the Netherlands.

Mielke E., L. Diaz Anadon and V. Narayanamurti (2010), Water Consumption of Energy Resource Extraction, Processing, and Conversion, Energy Technology Innovation Policy Discussion Paper Series, Discussion Paper No. 2010-15, Harvard Kennedy School.

Nordhaus, W.D. (1994), Managing the Global Commons: The Economics of the Greenhouse Effect, MIT Press, Cambridge, MA.

Nordhaus, W.D. (2007), A question of balance, Yale University Press, New Haven, United States. Nordhaus, W.D. (2010), "Economic aspects of global warming in a post-Copenhagen environment”, Proceedings of the National Academy of Sciences, Vol. 107(26), pp. 11721-11726.

OECD (2015), The Economic Consequences of Climate Change, Circle Project: OECD Environment Directorate: Paris.

OECD (2015), Water Resources Allocation: Sharing Risks and Opportunities, OECD Studies on Water, OECD Publishing, Paris. DOI: http://dx.doi.org/10.1787/9789264229631-en.

O’Neill B.C., E. Kriegler, K. Riahi, K.L. Ebi, S. Hallegatte, T.R. Carter, R. Mathur and D.P. van Vuuren (2014), “A new scenario framework for climate change research: the concept of shared socio- 
economic pathways”, Climatic Change, vol. 122, pp. 387-400.

Roson, R. and M. Sartori (2014), "Climate Change, Tourism and Water Resources in the Mediterranean: a General Equilibrium Analysis”, International Journal of Climate Change Strategies and Management, vol. 6(2), pp. 212- 228.

Roson, R. and M. Sartori (2015), "System-wide Implications of Changing Water Availability and Agricultural Productivity in the Mediterranean Economies”, Water Economics and Policy, vol. 1(1), pp. 1450001.1-30.

Roson, R. and M. Sartori (2016), Estimation of climate change damage functions for 140 regions in the GTAP9 database, World Bank Policy Research Working Papers, Washington D.C., forthcoming.

Roson, R. and D. van der Mensbrugghe (2012), "Climate Change and Economic Growth: Impacts and Interactions”, International Journal of Sustainable Economy, vol.4(3), pp. 270-285.

Taheripour F., Hertel T.W., Gopalakrishnan B.N. and Sahin, S. (2015), Low Water High Growth in the South Asian Economies, Purdue University and World Bank Joint Project Final Report, World Bank, Washington DC.

Tol, R.S.J. (2005). "Emission abatement versus development as strategies to reduce vulnerability to climate change: an application of FUND”, Environment and Development Economics, Vol. 10(5), pp. 615-629.

U.S. Energy Information Administration (2015), Monthly Energy Review, June 2015.

van Vuuren D.P., J. Edmonds, M. Kainuma, K. Riahi, A. Thomson, K. Hibbard, G.C. Hurtt, T. Kram, V. Krey, J.-F. Lamarque, T. Masui, M. Meinshausen, N. Nakicenovic, S.J. Smith and S.K. Rose (2011), “The representative concentration pathways: an overview”, Climatic Change, vol. 109, pp. 5-31.

World Bank (2015), The Critical Face of Climate Change, mimeo.

Worthington, A.C, and M. Hoffman (2006), A state of the art review of residential water demand modelling, University of Wollongong, School of Accounting and Finance Working Paper Series No. $06 / 27$. 